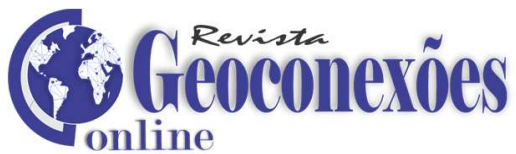

\section{O papel do FOCEM na discussão sobre a integração fronteiriça no MERCOSUL}

OLIVEIRA CRUZ, Dayana Aparecida Marques de ${ }^{1}$

Recebido (Received): 10/04/2021 Aceito (Accepted): 25/04/2021

Como citar este artigo: OLIVEIRA CRUZ, D. A. M. de. O papel do FOCEM na discussão sobre a integração fronteiriça no MERCOSUL. Geoconexões (online), v.1, n.1, p. 02-13, 2021.

RESUMO: Desde sua formação, o Mercado Comum do Sul (MERCOSUL) possui inúmeros desafios, dentre os quais destaca-se a integração fronteiriça. A integração fronteiriça no bloco contempla diferentes dimensões, todavia nota-se que a falta de infraestrutura adequada é o principal entrave para que ela de fato ocorra. Um dos motivos para a existência dos gargalos infraestruturais é a falta de recursos necessários para o investimento pelos Estados Nacionais. Neste sentido, o Fundo para a Convergência Estrutural do MERCOSUL (FOCEM), criado em 2004, possui um papel relevante ao propor a contribuição e distribuição de recursos considerando as assimetrias regionais. $O$ objetivo geral desse texto é debater sobre o papel do FOCEM na integração fronteiriça no MERCOSUL, a partir do financiamento de projetos de infraestruturas. A metodologia utilizada foi a revisão bibliográfica sobre 0 tema, bem como a análise de documentos e normativas publicadas pelo MERCOSUL.

PALAVRAS-CHAVE: Integração Fronteiriça. MERCOSUL. FOCEM.

\section{THE ROLE OF FOCEM IN THE DISCUSSION ABOUT BORDER INTEGRATION IN MERCOSUR}

\begin{abstract}
Since its formation, the Southern Common Market (MERCOSUR) has faced numerous challenges, among which border integration stands out. The border integration in the bloc contemplates different dimensions, however it is noted that the lack of adequate infrastructure is the main obstacle for it to actually occur. One of the reasons for the existence of infrastructure bottlenecks is the lack of resources needed for investment by National States. In this sense, the MERCOSUR Structural Convergence Fund (FOCEM), created in 2004, has a relevant role in proposing the contribution and distribution of resources considering regional asymmetries. The general objective of this text is to discuss the role of FOCEM in border integration in MERCOSUR, based on the financing of infrastructure projects. The methodology used was the bibliographic review on the topic, as well as the analysis of documents and regulations published by MERCOSUR.
\end{abstract}

KEYWORDS: Border Integration. MERCOSUR. FOCEM.

\footnotetext{
${ }^{1}$ Doutora em Geografia pela Universidade Estadual Paulista (UNESP) e graduada em Geografia. Email: d.dayana@hotmail.com. Orcid: https://orcid.org/0000-0001-5611-593X
}

Revista Geoconexões Online, v.1, n.1 (2021), 2021. P.2-13. 


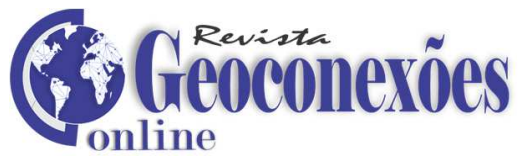

\section{Introdução}

O Mercado Comum do Sul (MERCOSUL) foi criado em 1991, no contexto do regionalismo aberto e de quebra dos acordos cobertos pelo Acordo Geral de Tarifas e Comércio (GATT). Regionalmente, o MERCOSUL conformou-se como uma resposta à imposição da Área de Livre Comércio das Américas (ALCA), ao mesmo tempo em que buscava a inserção competitiva dos países da Bacia do Prata no comércio internacional.

O MERCOSUL foi baseado na experiência europeia de integração, alheia à realidade histórica, geográfica, econômica e social do bloco. Em função disso, o intuito inicial de formação de um mercado comum nos primeiros quatro anos após a criação, foi uma meta frustrada. O MERCOSUL, permanece ainda hoje, trinta anos após sua fundação, como uma união aduaneira imperfeita, pois mantém uma lista de exceções para a Tarifa Externa Comum.

Mas, este não é o único desafio do bloco, pois desde sua fundação, os membros efetivos, também chamados de Estados Partes têm ampliado as discussões em torno da integração regional para além da perspectiva econômica. O grande desafio é a permanência das assimetrias no MERCOSUL que não permitem o aprofundamento do processo de integração. As assimetrias podem ser vistas nos indicadores socioeconômicos, nas condições das infraestruturas e na capacidade de investimento dos Estados que compõem o bloco.

Inicialmente, o MERCOSUL foi criado por Argentina, Brasil, Paraguai e Uruguai através da assinatura do Tratado de Assunção. A Venezuela passou a integrar o grupo de Estados Partes do bloco em 2012. Todavia, foi suspensa por período indeterminado em 2017 por conta da crise venezuelana e também pela mudança no cenário político regional, cujo marco foi a eleição de Maurício Macri na Argentina, e o impeachment da ex-presidente Dilma Rousseff no Brasil (ambos acontecimentos ocorridos em 2016).

O quadro político é fundamental para entender a dinâmica regional proposta no âmbito do MERCOSUL. Entre 2003 e 2015, o MERCOSUL vivenciou uma ampliação das discussões sobre a integração regional devido o giro à esquerda que a América do Sul vivenciou. Neste período, em 2004, foi criado o Fundo para a Convergência Estrutural do MERCOSUL (FOCEM). A proposta paraguaia endossada pelo Brasil materializou-se em um fundo estrutural que tem como premissa a tentativa de diminuição das assimetrias regionais. $A$ contribuição do fundo é fundamental para o fomento às redes de infraestruturas, sobretudo no Paraguai e no Uruguai, cuja capacidade dos agentes locais em arcar com os projetos neste setor é insuficiente.

Revista Geoconexões Online, v.1, n.1 (2021), 2021. P.2-13. 


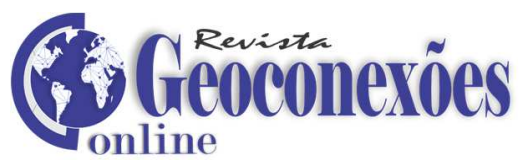

Apesar de ser uma proposta regional inovadora, o FOCEM possui alguns desafios, relacionados, dentre outras coisas, à própria organização intergovernamental do bloco e a ausência de mecanismos para a coordenação dos projetos no âmbito regional, que considerem também o planejamento local dos lugares em que as propostas serão implantadas.

O objetivo geral desse texto é debater sobre o papel do FOCEM na integração fronteiriça no MERCOSUL, a partir do financiamento de projetos de infraestruturas. A metodologia utilizada foi a revisão bibliográfica sobre o tema, bem como a análise de documentos e normativas publicadas pelo MERCOSUL.

O texto está dividido em duas partes principais, além da conclusão. A primeira parte denominada como "O debate sobre a integração fronteiriça no MERCOSUL" trata sobre as iniciativas que discutem a integração fronteiriça no bloco. A segunda parte, "O papel do FOCEM para o fomento da integração fronteiriça no MERCOSUL a partir das infraestruturas", indica a forma de organização, os projetos financiados e os desafios do fundo mercosulino.

\section{O debate sobre a integração fronteiriça no mercosul}

A questão fronteiriça é tratada no MERCOSUL no âmbito do FOCEM e o Grupo Ad Hoc de Integração Fronteiriça (GAHIF) (CARNEIRO FILHO; LEMOS, 2014). O GAHIF, criado em 2002 pelo Decreto n. 05/02, esteve relacionado às discussões mais amplas sobre o processo de integração nas fronteiras, enquanto o FOCEM dedica-se ao financiamento de projetos de infraestruturas nesses espaços. O objetivo do GAHIF é contribuir com o aumento da fluidez e harmonia das comunidades fronteiriças. Apesar da importância do diálogo sobre a integração fronteiriça, o grupo não teve muito êxito.

As poucas reuniões desenvolvidas aconteceram sem a representação das populações fronteiriças, só os governos nacionais participaram com total ausência de governos subnacionais, tratando a cooperação fronteiriça em uma lógica absolutamente top-down (SAUSI; ODDONE, 2010, p. 137 tradução livre da autora).

Além do GAHIF, Suasi e Oddone (2010) também destacam o Grupo de Trabalho de Integração Fronteiriça no MERCOSUL e o projeto criado por ele, "Integração Fronteiriça no MERCOSUL", financiado pela Agência Espanhola de Cooperação Internacional ao Desenvolvimento (AECID). 


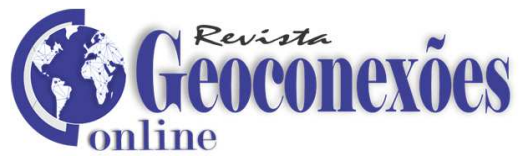

Embora essas iniciativas tenham sido relevantes, o pouco destaque para as discussões sobre a integração fronteiriça no bloco demonstra a fragilidade com que o tema é tratado. Observamos que este quadro é também uma herança do histórico do foco exclusivo sobre a questão econômica no MERCOSUL até 2003, bem como de uma recente busca pela flexibilização do bloco desde 2016.

Faz-se necessária a ampliação do debate sobre a integração fronteiriça no MERCOSUL que envolva diferentes temas como a questão trabalhista e sindical, a degradação ambiental, as migrações, e o acesso à saúde e à educação. É importante ressaltar que tais temas são discutidos de forma superficial e que ampliar as discussões também significa avançar concretamente nas ações em torno da integração fronteiriça. A superficialidade com que esses temas são tratados deve-se à própria natureza do MERCOSUL enquanto acordo intergovernamental.

O modelo intergovernamental está associado às crises institucionais, bem como às dificuldades de solução de controvérsias no bloco em decorrência da burocratização do processo de integração (KERBER, 2000). No modelo intergovernamental não há obrigatoriedade no acato de decisões pelos Estados Partes, a obrigatoriedade de internalização as normas e regras do MERCOSUL só seria requerida caso o acordo fosse supranacional. A supranacionalidade só seria possível no bloco caso as constituições dos respectivos Estados Partes indicassem essa possibilidade. Embora a Venezuela, o Paraguai e a Argentina indiquem em suas constituições tal possibilidade, nas constituições do Brasil e do Uruguai não há indicações sobre o assunto por serem, inclusive, anteriores à criação do bloco (CRUZ, 2017).

$\mathrm{Na}$ falta do debate intrabloco, os membros do MERCOSUL possuem acordos bilaterais que tratam sobre a questão fronteiriça. Carneiro Filho e Lemos (2014) citam como exemplos: a Nova Agenda para Cooperação e Desenvolvimento Fronteiriço entre Brasil e Uruguai (2002) e o decorrente Acordo para Permissão de Residência, Estudo e Trabalho a Nacionais e Fronteiriços Brasileiros e Uruguaios em vinte quilômetros a partir da fronteira²; e a Declaração Conjunta de Brasília entre Brasil e Argentina (2003) que resultou na elaboração de projetos pilotos de ensino bilingue na fronteira. Suasi e Oddone (2010) incluem também o Foro de Cooperação Transfronteiriça Argentina-Brasil-Paraguai "Cooperação Sul-Sul para a Integração" realizado em 2009, e as discussões sobre população e fronteira feitas no âmbito do Comitê Interinstitucional de População do Ministério do Interior do Paraguai.

\footnotetext{
2 O Brasil propôs estender esse acordo a todo o MERCOSUL, porém o Paraguai decidiu manter esse tipo de negociação no nível bilateral (SAUSI; ODDONE, 2010).
} 


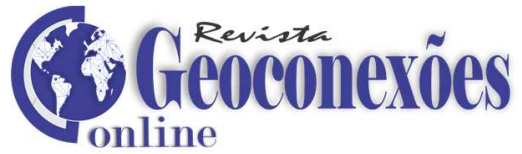

Além da discussão no âmbito da circulação de pessoas nas fronteiras mercosulinas, há ainda o debate em relação às infraestruturas, protagonizado pelo FOCEM.

\section{O papel do focem para o fomento da integração fronteiriça no mercosul a partir das infraestruturas}

Como é sabido, a ocupação dos territórios sul-americanos foi iniciada pelo litoral, caracterizando o adensamento populacional e de infraestruturas nestes espaços. Daí a necessidade de fomento às infraestruturas nas fronteiras do bloco, sobretudo em relação às zonas fronteiriças com o Paraguai, que é o único país mediterrâneo do MERCOSUL. O desenvolvimento de projetos nesses espaços fronteiriços é um desafio, pois os países não possuem as mesmas condições para o financiamento e execução dos projetos, o que está ligado às condições semiperiférica e periférica que ocupam no sistema-mundo. Cabe ressaltar que a necessidade de investimento em infraestruturas não é uma questão particular do MERCOSUL, mas é uma demanda comum em toda a América Latina.

O padrão de ocupação sul-americano e a concentração dos núcleos urbanos no litoral do subcontinente resultaram em uma herança histórica de concentração do contingente populacional regional. A interiorização da rede de infraestruturas tornou-se um desafio, tanto do ponto de vista das características físicas do território, como pela ausência de recursos suficientes para promovê-la (CRUZ, 2019, p. 49).

Os projetos e infraestruturas são fundamentais, sobretudo porque esses países desempenham o papel de produção e exportação de commodities na divisão territorial do trabalho, demandando, portanto, grandes projetos em diferentes modais para suprir às demandas dos fluxos no comércio internacional. No âmbito do MERCOSUL, o FOCEM tem um papel relevante para a integração fronteiriça do ponto de vista das infraestruturas.

O FOCEM foi criado através da decisão CMC n 45/04, no ano de 2004. Inicialmente, o FOCEM teria a duração de apenas dez anos, mas em 2015 o prazo foi prorrogado por mais dez anos, devendo exercer suas atividades até janeiro de 2026, a partir da Decisão n. 22/15 (CRUZ, 2019).

O intuito do FOCEM é contribuir para a diminuição das assimetrias no bloco, considerando o histórico do Produto Interno Bruto (PIB) dos Estados Partes como referência para a contribuição anual não-reembolsável e a disponibilidade de recursos. Os gráficos a seguir (Figuras 1 e 2) mostram o percentual de contribuições e de disponibilidade de recursos do FOCEM, no período de 2012-2015. Os gráficos compreendem, portanto, o período de participação da Venezuela e, por isso, indicam o percentual dos cinco Estados Partes. Em 


\section{Ge Geacoconerốes}

decorrência da proposta do FOCEM de diminuição das assimetrias, os países com maior PIB contribuem com maior montante anual e têm menor disponibilidade de financiamento. Já os países com menor PIB contribuem com menor montante anual, porém têm uma porcentagem maior do fundo disponível para o financiamento de seus projetos.

O fundo de cem milhões de dólares entrou em vigor no ano de 2007. Após a entrada da Venezuela no MERCOSUL o fundo passou a ter o valor total de contribuições de cento e vinte e sete milhões de dólares, permanecendo com este montante de contribuição entre 20122015, seguindo o percentual apresentado nos gráficos anteriores.

Com a suspensão da Venezuela por tempo indeterminado, o FOCEM voltou a ter o montante de contribuição anual de cem milhões de dólares. A Venezuela foi suspensa em função do descumprimento do Protocolo de Ushuaia sobre Compromisso Democrático no MERCOSUL, sendo que a suspensão foi feita oficialmente através da Declaração dos Estados Partes do MERCOSUL sobre a República Bolivariana da Venezuela, assinada no dia 10 de abril de 2017.

Caso a suspensão seja revogada, a distribuição dos recursos e contribuições voltará a vigorar de acordo com os gráficos (Figuras 1 e 2), assim como foi feito na ocasião de suspensão do Paraguai em 2012. Enquanto a Venezuela estiver suspensa, o FOCEM retorna à contribuição e distribuição de recursos feitas no momento de sua criação, sendo a contribuição de 27\% para Argentina; 70\% para o Brasil; $1 \%$ para o Paraguai e $2 \%$ para o Uruguai; e a distribuição de recursos de 48\% para o Paraguai; 32\% para o Uruguai; $10 \%$ para a Argentina e 10\% para o Brasil (MERCOSUL, 2005).

Figura 1 - Porcentagem de contribuição anual não reembolsável

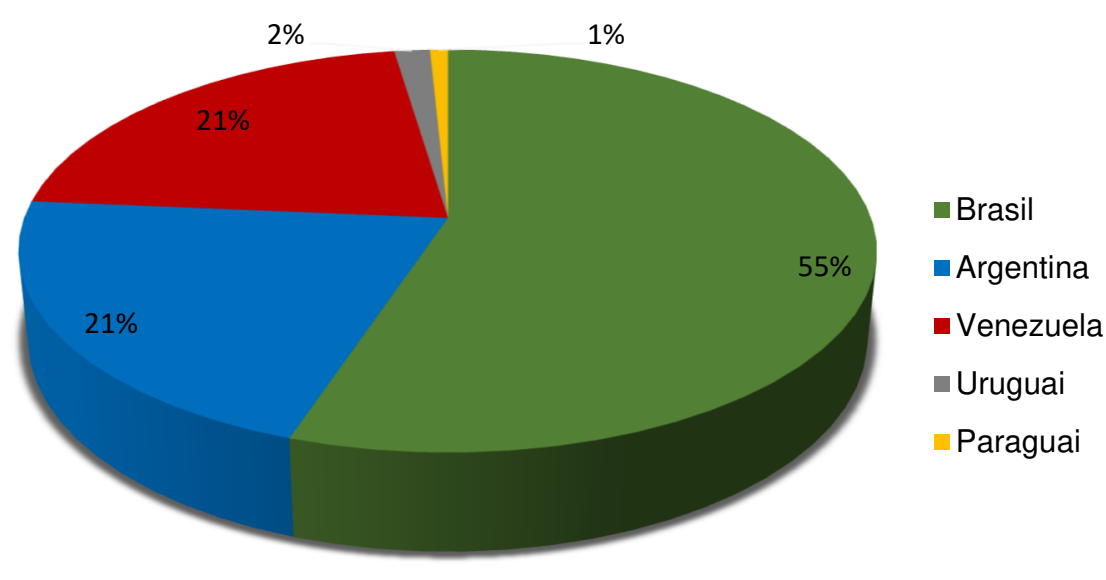

Fonte dos dados: MERCOSUL (2015).

$\overline{\operatorname{Revi}}$

Elaborado pela autora. 


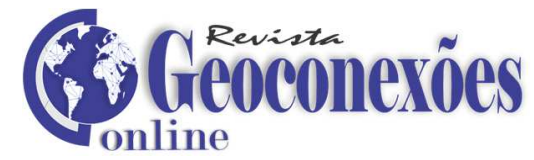

Figura 2 - Porcentagem de valor disponível para o financiamento de projetos

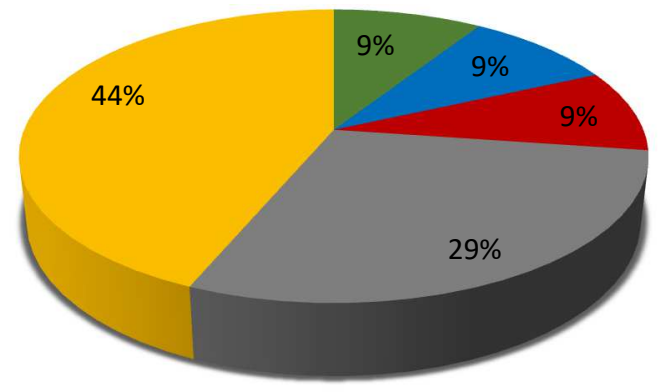

Brasil

- Argentina

- Venezuela

- Uruguai

Fonte dos dados: MERCOSUL (2015).

Elaborado pela autora.

O FOCEM contempla quatro Programas diferentes, nos quais os projetos devem estar enquadrados. São eles: 1. Convergência estrutural - diminuição das assimetrias, com foco na melhoria dos sistemas de transportes e comunicações e a integração fronteiriça; 2. Desenvolvimento da competitividade - cooperação em ciências, tecnologia e integração produtiva; 3. Coesão social - ênfase em projetos de saúde, educação e redução da pobreza e do desemprego nas zonas fronteiriças; 4. Fortalecimento da estrutura institucional e do processo de integração (CRUZ, 2017).

Dos programas citados, a prioridade é o Programa 1, que inclui projetos de infraestruturas, tais como: saneamento, transportes e energia. Por conta dos gargalos infraestruturais da região, sobretudo no Paraguai e no Uruguai, durante os primeiros anos de seu funcionamento, o FOCEM priorizou os projetos enquadrados no Programa 1 (MERCOSUL, 2015). Em 2015, a distribuição dos projetos aprovados pelo FOCEM apresentava-se da seguinte forma de acordo com a distribuição dos programas: programa 1 - $43 \%$ dos projetos; programa $2-29 \%$ dos projetos; programa $3-16 \%$ dos projetos; programa $4-12 \%$ dos projetos (MERCOSUL, 2015), conforme consta o gráfico a seguir (Figura 3).

Figura 3 - Distribuição dos projetos aprovados por programa

Revista Gec
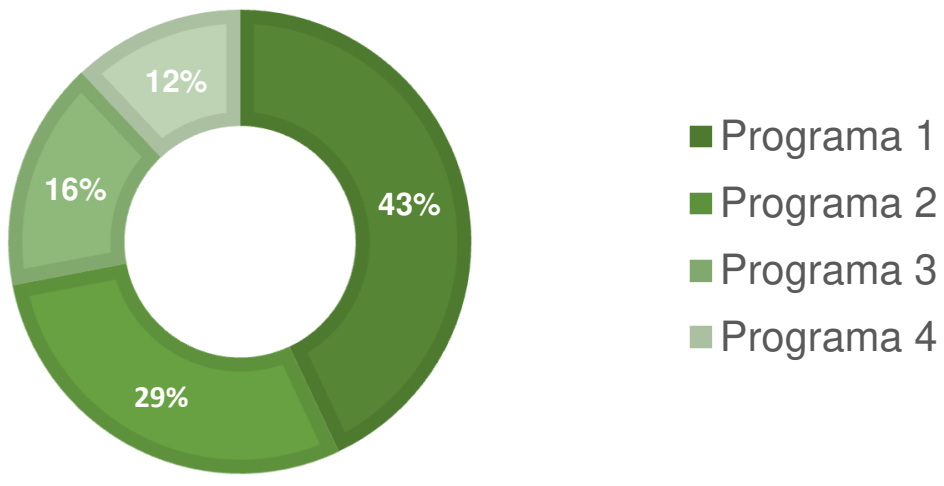

Fonte dos dados: MERCOSUL (2015).

Elaborado pela autora. 


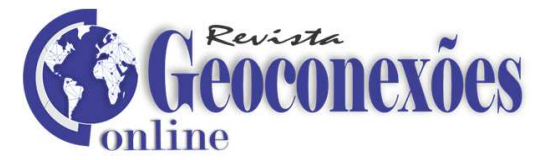

Os principais projetos financiados pelo programa 1 - Convergência Estrutural são: Implantação do sistema de 500 kv no Paraguai; Interconexão elétrica de 500 MW entre Brasil e Paraguai; Construção da Avenida Costanera Norte de Assunção no Paraguai; Reabilitação e melhoramento de estradas de acesso e circulação da Grande Assunção no Paraguai; Recapeamento do trecho alimentador das rodovias 1 e 6 no Paraguai; Ampliação do sistema de saneamento de Ponta Porã no Brasil; Reabilitação de ferrovias no Uruguai.

Todos esses projetos tem como foco a implantação ou revitalização da infraestrutura física, com impactos diretos na integração fronteiriça, seja porque a localização das obras inclui as regiões fronteiriças, ou ainda, porque o desenvolvimento da proposta buscar tornar mais fluida e eficiente a rede que está conectada a essas regiões fronteiriças. Observamos também, que os projetos buscam promover a conectividade entre regiões mais dinâmicas economicamente e as regiões fronteiriças dos respectivos países. Podemos citar o exemplo do projeto finalizado de "Reabilitação e melhoramento de estradas de acesso e circulação da Grande Assunção no Paraguai", com contribuição de doze milhões e seiscentos mil dólares do FOCEM. O projeto reduziu em quarenta por cento as viagens e atraiu novas atividades comerciais em suas zonas de influência (MERCOSUL 2015). É fundamental ressaltar que a Grande Assunção está conectada às rotas n. 2 e 7 a partir das quais é possível ter acesso à Ponte da Amizade entre Ciudad del Este e Foz do Iguaçu.

Até o ano de 2015 o FOCEM teve 43 projetos aprovados e contou com o total de contribuições de um bilhão de dólares (MERCOSUL, 2015). O processo de aprovação dos projetos consiste na submissão à Comissão de Representantes Permanentes do MERCOSUL (CRPM). A CRPM verifica se o projeto está de acordo com as exigências para a submissão da proposta. São elas: enquadramento aos objetivos do FOCEM; inclusão da proposta em um dos quatros programas; apresentação do conteúdo obrigatório para a elaboração da documentação; indicação da responsabilidade do setor público na execução do projeto; apresentação do valor total da proposta, devendo ser superior a quinhentos mil dólares de investimento; indicação do retorno socioeconômico superior à taxa de rentabilidade social; apresentação de um projeto novo que não deve substituir outros projetos em execução; previsão das ações de mitigação de danos ambientais; consideração das especificidades culturais, sociais, econômicas e geográficas do território (MERCOSUL, 2015).

Uma vez que o projeto está de acordo com os critérios de elegibilidade, ele é avaliado pelas respectivas Unidades Técnicas Nacionais FOCEM (UTNF). A versão final do projeto é encaminhada à CRPM que elabora um parecer para o Grupo Mercado Comum (GMC). Na condição de ser aprovado, o parecer e o projeto são enviados ao Conselho Mercado Comum

Revista Geoconexões Online, v.1, n.1 (2021), 2021. P.2-13. 


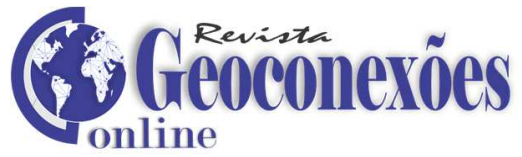

(CMC). O CMC aprova a decisão e o FOCEM faz a designação dos recursos. Obviamente, a quantidade de projetos e o montante necessário para desenvolvê-lo seguirá o percentual de distribuição do fundo que é destinado a cada país. Caso o país não utilize o total dos recursos no ano corrente, o valor destinado é cumulativo para o ano seguinte.

Para Severo e Lima (2020), considerando o histórico do FOCEM, podemos indicar três fases distintas de desenvolvimento do fundo. A primeira corresponde ao período de 2006 a 2010 no qual o fundo teria passado pela adaptação técnico-burocrática e de acúmulo de recursos, essa fase corresponde ao início do funcionamento do FOCEM e remonta às primeiras decisões relacionadas ao arcabouço organizacional e aos primeiros projetos submetidos e aprovados. A segunda fase, entre 2011 e 2015 foi caracterizada pelo financiamento de infraestrutura física, sobretudo no Paraguai e no Uruguai, países cuja capacidade financeira de arcar com os custos de projeto de grande magnitude é reduzida. Por fim, a terceira e atual fase, iniciada em 2016, é a do congelamento das iniciativas de integração regional. Cabe ressaltar que essa última fase apresentada por Severo e Lima (2020) não se limita apenas ao FOCEM ou ao MERCOSUL, mas abrange todos os blocos e acordos sul-americanos, estando ligada às mudanças no cenário político regional e sua orientação política à direita ou extrema direita. Juntamente com esse novo rumo tomado em 2016, vimos o endossamento do discurso pró-flexibilização do MERCOSUL, o desmantelamento da União de Nações Sul-americanas (UNASUL) e a criação do Foro para o Progresso da América do Sul (PROSUL) (CRUZ, 2020). Recentemente, a partir de 2018, o FOCEM estaria entrando também em uma nova fase de mudança organizacional, já que o Fundo Financeiro para o Desenvolvimento da Bacia do Prata (FONPLATA) passou a ser o administrador fiduciário e de convênios de complementação financeira e técnica (SEVERO; LIMA, 2020).

Um dos problemas do FOCEM é o orçamento aquém da necessidade dos Estados Partes, sobretudo dos membros menores (Paraguai e Uruguai). Segundo Misso (2019) isso acontece em virtude da limitação do montante de cem milhões de dólares diante das desigualdades e assimetrias existentes no MERCOSUL. Tessari (2012) argumenta que o baixo valor do FOCEM se deve à tentativa de conciliar a compensação financeira que o bloco propõe a partir do fundo, porém, sem onerar financeiramente os membros maiores (Argentina e Brasil).

Cruz (2019) ressalta que os tipos de projetos financiados são diferentes nos membros maiores (Argentina e Brasil) e nos membros menores (Paraguai e Uruguai). Para a autora, o motivo é o alto custo para a execução dos projetos de infraestruturas, pois o Brasil, por 


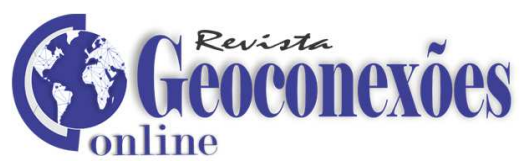

exemplo, possui o Banco Nacional de Desenvolvimento Econômico e Social (BNDES) para o financiamento de seus projetos, no caso do Paraguai e do Uruguai não há um aparato financeiro e nacional de grande magnitude para o apoio à execução das obras.

\begin{abstract}
No geral, Paraguai e Uruguai utilizam o recurso disponível para o financiamento de projetos de infraestruturas, sobretudo para infraestruturas de transportes e energia. No caso do Paraguai, a porcentagem de recursos utilizados para este fim varia entre $70 \%$ e $80 \%$ do total disponibilizado. Para os demais membros do bloco, sobretudo o Brasil, o fomento às infraestruturas de transportes nesses países são fundamentais por possibilitarem maior fluidez para a circulação de mercadorias, diminuição dos custos logísticos, além de beneficiar as empresas brasileiras que atuam nesses países, principalmente no Paraguai, cujos principais setores de atuação são o agronegócio e os frigoríficos (CRUZ, 2018, p. 41-42).
\end{abstract}

De 2007 a 2020, do total disponível para o financiamento de projetos, cerca de $94 \%$ do montante foi destinado ao Paraguai e ao Uruguai, garantindo a viabilidade de alguns projetos que não poderiam ser executados se dependesse dos recursos locais (SEVERO; LIMA, 2020). Só no Paraguai, "foi financiado o investimento para um total de 432 km de caminhos" (MERCOSUL, 2015, p. 8).

Uma crítica à distribuição dos recursos é que ela não acontece a partir de uma diretriz supranacional ou de um planejamento macrorregional, nem tampouco articula-se com os planos regionais ou locais (MISSO, 2019). Neste sentido, o MERCOSUL precisa criar mecanismos não só no FOCEM, mas em outras instâncias do bloco que promova uma coordenação efetiva do planejamento regional, bem como da destinação de recursos. Ademais, é preciso ainda estabelecer formas de garantir o diálogo com a população que vive próximo aos espaços que receberão os projetos, afinal existe uma série de implicações culturais, ambientais e sociais que precisam ser consideradas não só nos estudos prévios feitos pelos técnicos, mas que precisam ser apontados a partir do diálogo com os cidadãos.

\section{Considerações finais}

Apesar de relevante, a integração fronteiriça no MERCOSUL é um tema que carece de maior debate no âmbito da agenda internacional dos países que fazem parte do bloco. FOCEM tem um papel relevante nessa discussão, pois verifica-se a falta de infraestruturas para a promoção da integração fronteiriça, sobretudo nos membros menores do bloco que não tem condições financeiras de arcar com os custos da integração.

Revista Geoconexões Online, v.1, n.1 (2021), 2021. P.2-13. 


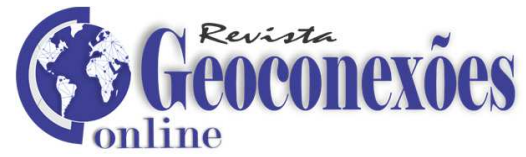

Por adotar como referência a desigualdade histórica do PIB entre os Estados Partes, o FOCEM constitui-se como uma proposta inovadora na região, ainda que o montante disponível para o fundo esteja aquém da demanda de projetos que precisa ser atendida. Um ponto fundamental a ser ressaltado é que desde sua fundação, o montante disponível para o financiamento de projetos não foi revisto, ou seja, permanece em torno de cem milhões de dólares anuais, com exceção do período de 2012-2015 por conta da contribuição venezuelana.

A suspensão da Venezuela gerou um grande impacto no FOCEM, pois diminuiu a entrada anual de vinte e sete milhões de dólares. Considerando todo o período de existência do FOCEM observamos que houve grande desvalorização das moedas regionais, sobretudo do real, porém o valor de contribuição e de disponibilidade de recursos permaneceu estagnado. Há ainda o fato adicional de que desde 2012 a Bolívia está em processo de adesão ao bloco, caso esse processo seja concluído, a Bolívia terá um perfil semelhante ao do Paraguai no FOCEM: maior valor disponível para financiamento de projetos e baixa contribuição. Se o fundo continuar sendo de cem milhões de dólares pouco poderá ser feito em relação ao fomento às infraestruturas e à integração fronteiriça.

Nos últimos anos, apesar da prorrogação do período de atuação do FOCEM, nota-se um enfraquecimento do fundo que advém das mudanças no cenário político regional. Os efeitos deste enfraquecimento são severos, afinal, mesmo no período de 2004-2015 em que a cooperação sul-sul era valorizada na agenda dos países da região, o FOCEM já esbarrava em desafios estruturais como o já citado montante disponível para o fundo; a falta de coordenação entre os projetos propostos e o planejamento macrorregional e local; a ausência na participação dos cidadãos afetados diretamente pelos projetos; a estrutura intergovernamental do MERCOSUL e a dificuldade de internalização dos países em relação às normas e aos objetivos estabelecidos no bloco.

Os desafios pretéritos do FOCEM, neste momento de crise política, econômica e sanitária foram ampliados. Ao mesmo tempo em que o FOCEM poderá contribuir com o período pós-covid, por outro lado, os impactos da crise no MERCOSUL contribuem para o enfraquecimento do bloco e do fundo. Neste momento, o MERCOSUL não tem indicado orientações que possam contribuir para a diminuição dos impactos da crise ocasionada pelo COVID-19. O FOCEM poderia estar sendo um dos pilares na discussão sobre este tema. 


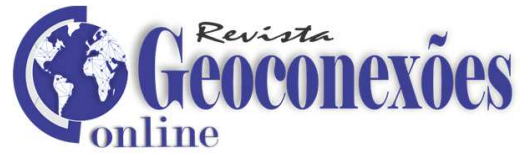

\section{Referências}

CARNEIRO FILHO, Camilo Pereira; LEMOS, Bruno de Oliveira. Brasil e MERCOSUL: Iniciativas de cooperação fronteiriça. ACTA Geográfica, Boa vista, Edição Especial de Geografia Política e Geopolítica, p. 203-2019, 2014. Disponível em: https://revista.ufrr.br/actageo/article/view/2448/1445, acesso em 03 de abril de 2021.

CRUZ, Dayana Aparecida Marques de Oliveira. Geopolítica e integração regional: uma análise dos projetos de infraestrutura de transportes entre Brasil e Paraguai. Tese. Doutorado em Geografia. Presidente Prudente: UNESP, 2017. Disponível em:

https://repositorio.unesp.br/handle/11449/152394, acesso em 30 de janeiro de 2021.

O papel do Brasil no processo de integração regional no MERCOSUL. Revista Formação (Online), v. 25, n. 46, p. 27-45, 2018. Disponível em:

https://revista.fct.unesp.br/index.php/formacao/article/view/5506, acesso em 21 de março de 2021. https://doi.org/10.33081/formacao.v25i46.5506

O Fundo para a Convergência Estrutural do MERCOSUL (FOCEM): um debate sobre assimetrias e integração regional. GEOgraphia, v. 21, n. 47, p. 43-51, 2019. Disponível em: https://periodicos.uff.br/geographia/article/view/28174/23460, acesso em 23 de março de 2021. https://doi.org/10.22409/GEOgraphia2019.v21i47.a28174

Os rumos da integração regional no subcontinente: da UNASUL ao PROSUL, o que mudou? Revista de Geopolítica, v. 11, n. 4, p. 111-122, 2020. Disponível em:

http://www.revistageopolitica.com.br/index.php/revistageopolitica/article/view/306/260, acesso em 04 de abril de 2021.

KERBER, Gilberto. MERCOSUL e supranacionalidade: um estudo à luz das legislações constitucionais. Dissertação. Mestrado em Direito. Florianópolis: UFSC, 2000. Disponível em: https://repositorio.ufsc.br/xmlui/bitstream/handle/123456789/78226/170264.pdf?sequence=1\&isAllowe $\mathrm{d}=\mathrm{y}$, acesso em 04 de abril de 2021.

MERCOSUL. O Fundo para a Convergência Estrutural do MERCOSUL - FOCEM (2005-2015). Unidade Técnica FOCEM - UTF, Secretaria do MERCOSUL, 2015.

MERCOSUL/CMC/DEC n. 18/05. Disponível em:

https://focem.mercosur.int/uploads/normativa/DEC_018-2005_PT_FERR_IntegFuncFOCEM-2.pdf, acesso em 19 de abril de 2021.

MISSO, Fabricio José. O Fundo para a Convergência Estrutural como instrumento de desenvolvimento regional do MERCOSUL. Cadernos CEPEC, v. 08, n. 1, p. 25-42, 2019. Disponível em: https://periodicos.ufpa.br/index.php/cepec/article/view/7763, acesso em 20 de março de 2021. https://doi.org/10.18542/cepec.v8i1.7763

SAUSI, José Luis Rhi; ODDONE, Nahuel. La cooperación transfronteriza entre las unidades subnacionales del MERCOSUR. Tendencias. Revista de la Facultad de Ciencias Económicas y Administrativas, v. XI, n. 2, p. 131-159, 2010. Disponível em:

https://core.ac.uk/download/pdf/147428141.pdf, acesso em 30 de março de 2021.

SEVERO, Luciano Wexell; LIMA, Mônica Karla Magalhães. Los 15 años del FOCEM. Revista Tempo do Mundo, v. 23, p. 256-284, 2020. Disponível em:

https://www.ipea.gov.br/revistas/index.php/rtm/article/view/175, acesso em 08 de abril de 2021. https://doi.org/10.38116/rtm23art10

TESSARI, Gustavo Rosolen. Integração regional, fundos estruturais e estabilidade institucional no MERCOSUL: a criação do FOCEM. Perspectivas, São Paulo, v. 42, p. 115-137, 2012. Disponível em: https://periodicos.fclar.unesp.br/perspectivas/article/view/5942, acesso em 10 de fevereiro de 2021 